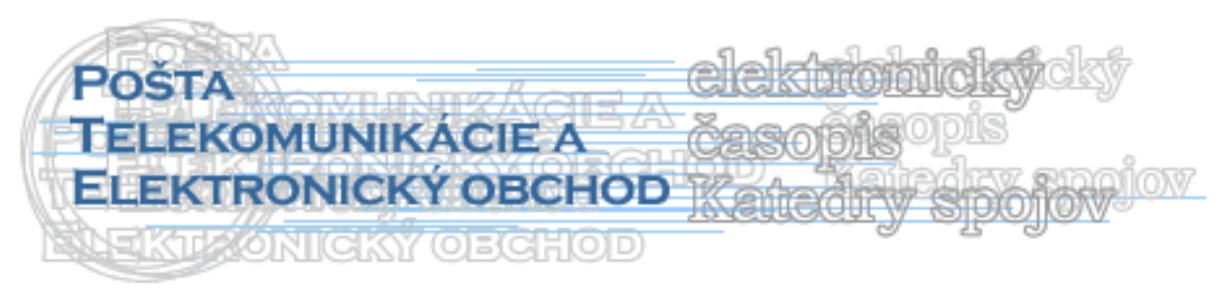

\title{
OUTSOURCING THE ACCOUNTING DEPARTMENT
}

\author{
Lucia Krátka*
}

\section{Introduction}

Organizations around the world are increasingly considering outsourcing as a strategic management tool, which can be leveraged to allow them to focus on their core competencies. Outsourcing is viewed as a means to reduce costs, improve customer satisfaction, and provide enhanced efficiency and effectiveness. However, many organizations never realize the full benefits of an outsourcing relationship.

\section{Managing the outsourcing process}

Outsourcing relationships fail when they are viewed as short-term or tactical solutions, rather than part of long-term strategic plans. The process of considering and/or implementing an outsourcing solution must be systematic and fully documented to achieve the desired results. A multi-step approach, includig Planning, Analysis, Design, Implementation, and Operations phases, along with a contingency exit strategy, is required to achieve a successful outsourcing implementation.

\section{Phase One: Planning Strategy}

Traditionally, outsourcing initiatives focused on headcount or cost reductions. Today, however, outsourcing is a more strategic decision, focusing on core competencies. Thus, it must have the full support of senior management, and all goals and objectives must be articulated from the top.

Before outsourcing a business function, a strategy and goals document should be drawn up, detailing the organization's outsourcing intentions, the strategic rationale for outsourcing, and describing:

- processes to be outsourced

- objectives for outsourcing

- relationship of outsourcing to the overall corporate strategy

- links between the outsourced process and the organization's core competencies

- strategic forces driving the organization into an outsourcing relationship

- scope of coverage

- critical risks involved

- expected duration of the relationship

\footnotetext{
* Ing. Lucia Krátka, Țilinská univerzita $\mathrm{v}$ Țiline, Fakulta prevádzky a ekonomiky dopravy a spojov, Katedra spojov, Univerzitná 1, 01026 Țilina, e-mail: kratka@fpedas.uniza.sk
} 


\section{Expected benefits of outsourcing}

Typically, organizations can expect to realize the following benefits from a strategic outsourcing initiative:

1. improved company focus, leaving operational details to the outside experts,

2. reduced operating costs,

3. increased customer satisfaction,

4. re-allocation of internal resources to core actiovities,

5. Access to world class capabilities and services, without the need to build from the bottom up,

6. reduced risk. Markets, competition, government regulations, financial conditions and Technologies all change extremely quickly,

7. improved cost, quality service and cycle time,

8. cash infusion. In some cases, outsourcing involves a transfer or sale of company assets to the provides,

9. increased capital funds availability. Resources can be acquired through alternate methods rather than capital expenditures.

\section{Phase Two: Analysis}

Phase Two involves preparing and delivering a request for proposal, examining proposals, evaluating outsourcing providers, and determining required service levels.

\section{Request for proposal}

The request for proposal itself should provide a complete pisture of every aspect of the business function to be outsourced. Vagueness in the content of an request for proposal results in outsourcing providers submitting proposals based on assumptions about deliverables, which could quite possibly result in increased costs over the life of the outsourcing agreement.

\section{Finding the „Right" outsourcing partner}

In the ideal relationship, both the organization and outsourcing provider share a similar vision and contribute equally to the success of the project. The right partner can help the outsourcer define realistic expectations and articulate benefits of moving the process outside.

Finding an outsourcing partner that can share your vision and merge seamlessly into your organization's culture requires significant up-front effort. Several formal and informal meetings will be required get to know one another, to achieve a complete understanding of the scope of the project, and to fully discuss the specifics of the processes and procedures.

\section{Determining financial benefits of outsourcing}

In evaluating the financial ramifications of outsourcing a business process, organizations othen employ a methodology, comparing the bid of one outsourcing provider to the bid of another. Then comparing the winning bid to the straight costs of performing the process intrenally. This method fails to consider the true impact of outsourcing. [6]

\section{Phase Three: Design}

\section{The Contract}

A sound agreement is critical to the success or failure of an outsourcing engagement. It allows the organization to maximize the rewards of outsourcing, while minimizing the risk. Each party mus understand the reasons for the outsourcing decision and approach the 
contracting process with a give and take philosophy. It is essential that the outsourcing contract reflect all the critical issues, specifically the scope, performance, and pricing.

\section{Service Level Agreements}

Properly structured performance incentives and penalties enable the outsourcing provider to work with your organization as a partner, be accountable for their performance, and tangibly demostrate the value they bring to your organization. The most successful outsourcing relationships involve the outsourcing provider and the organization participating in continuous process improvements.

\section{Phase Four: Implementation}

During the implementation phase, the transition from in-house provision of services to outsourcing is made. To ensure complete capture of all critical elements of a project, the outsourcing provider should adhere to a formal project management process, including:

- assignment of a dedicated project manager - project manager manages all phases of implementation and controls project planning, task assignments, project issues and resolution, status reporting, along with any direct client contact necessary to manage and control the project deliverables.

- completion of a requirements study - the document generated by the Sudy details the organization's system needs and how these needs will be implemented in the environment

- establishment of a project timeline with designated milestones and sign-offs - these sign-offs serve to indicate an agreement between the outsourcing provider and the organization that the specified deliverable has been completed to the satisfaction of both parties

- report customization - the outsourcing provider can assist in determining the design and data content of requisite reports

- system design, development, and configuration - this is where the process of building the outsourcing solution actually begins. Recommendations of test scenarios and test guidelines are created. All necessary code is developed and integrated into the system. At this stage, all documentation is finally completed.

- system testing - a plan is established to ensure that the solution developed by the outsourcing provider works correctly, is complete, and meets the organization's specifications as previously outlined in the difinition of project requirements.

- transition to "go live" - this is final stage of project implementation. Once the project has been designed, developed, configured, and tested, i tis ready to be activated. [6]

\section{Phase Five: Operations}

The outsourcing provider should appoint a dedicated account manager, who will be resident at their location, but travel widely throughout the customer organization. The organization should assign a project manager or single point of contact, who is knowledgeable in terms of the outsourced infrastructure and its cost drevers. This management team then becomes responsible for establishing and maintaining open communication channels and ensuring the success of the project. 


\section{Measuring Success}

A powerful technique for managing the outsourcing relationship and measuring its success is the use of balanced scorecards. Balanced scorecards include categories representing the most general level of expectations - usually built around cost, service, and quality. Within each category, specific attributes are defined through a joint buyer-provider process, with the exact composition and number depending on the goals of the relationship and the service in question.

\section{Terminating an outsourcing relationship}

In most cases, following the steps outlined above will result in an outsourcing solution that is viable over the long term. However, sometimes even the most carefully considered and well-structured plan can break down, requiring termination of the outsourcing relationship. This may be the result of cause or convenience, but in either case, a pre-defined ext strategy and termination plan is essential.[6]

\section{Outsourcing functions of accounting department}

The cornerstone of operations for most companies is the accounting department. It pays the bills, issues invoices to customers, monitors cash flow, pays employees, and keeps track of assets. It provides services to every functional area of the company. Without an accounting department, a company would not be able to function for more than a few days. There are a number of highly specialized functions that can be performed better or more efficiently by suppliers than internally. In these cases, the ultimate way to decrease cost and increase efficiency is to hand over portions of the accounting department to someone else.

The person who normally oversees the outsourcing work of any accounting suppliers is the controller. This person is the most highly trained in all accounting functions, and so is in the best position to oversee suppliers. If the accounting tasks being outsourced involve a very large volume of work, $i$ tis also possible that the controller or assistant controller will require some help in reviewing supplier work. If so, a small team of analysts may also be needed for the review of work products, transactional quality, and performance measurement.

\subsection{Advantages of outsourcing}

Payroll - this is the most commonly outsourced of all functions. It involves the use of detailed payroll tax calculations and govern mental remittances that many companies simply do not want to be bothered with, so they are willing to pay a Premium to a supplier who is an expet in these matters. Furthermore, if a company were to miss a payroll tax payment for any reason, there would be a stiff penalty fine. Usually, the avoidance of just a few of these fines per year will pay for the entire cost of outsourcing. Outsourcing payroll also allows a company to avoid the cost of periodically updating its own payroll software and associated tax tables. It alwo gains the use of direct deposit of pay to employee bank accounts, which is a difficult proposition if handled internally. The supplier can also handle clerical tasks, sucha s stuffing all cecks or deposit advices into envelopes. Suppliers can even link employees directly to a pension plan, so that the human resources department no longer has to make a separate payroll report to a plan administrator - virtually all paperwork is handled automatically by the supplier.

Collections - if this function is ousourced, the supplier will pursue collections much more aggressively than is sometimes the case with the in-house staff becouse they need to earn their Money.[1] 
Internal auditing - there are many advantages to outsource this function. Large audit firms contains many auditors with a broad mix of experience and skills, who can be swapped in and out of a company's internal audit work to best match skills with skill requirements. There will also probably be a high level of audit oversite, since this is all the auditing firm does, and so will have developed considerable audit planning and execution skills. Furthermore, they are an entirely variable cost - when an internal audit is done, the auditors leave, and there is no further charge for their services. Also, if the audit firm has numerous offices, then travel costs can be reduced for audits of outlying location by assigning auditors from the local Office to the nearest company location. Finally, there will be no hiring or training costs for the auditors, since this is all handled by the outsourcer auditin firm.

Taxation reporting - a smaller firm usually cannot afford the services of even a single taxation specialist, and so prefers to pay by the hour for advice from an outside expert who only needs to be called in from time to time. A very large firm will side step high fees charged by outside taxation experts and bring the entire function in-house.

Financial statement preparation - a very small firm may have no experienced accountant available, only clerical staff, and so has an outside accounting firm create financial statements from the books of record once a month. A much more common situation is to have outside auditors review the format and accompanying notes of the prepared financial statements from time to time, just to ensure that they comply with generally accepted accounting principles. This is especially true if a company is publicly held, and does not have a firm grasp of all the necessary public reporting requirements.

Transaction processing - a few of the largest companies have succeeded in shifting tehir entire accounting ransaction processing functions over to suppliers. This means that a minimum of all accounts payable and receivable are shifted to a supplier, but this typically results in virtually all accounting activities being outsourced. This makes sense when a supplier has achieved a high knowledge and practical use of accounting best practices that result in lower processing costs that can be passed along to the company. I tis also a reasonable alternative if a company's accounting functions are highly fragmented in numerous locations, and can be profitablz centraliyed. Another reason for this switch is that a company may have had trouble finding good management for its accounting function and would now prefer not to be bothered with a loss of management focus in this area.[1]

\subsection{Disadvantages of outsourcing}

Payroll - it costs substantially more to have a supplier process a company's payroll than it would to do it internally. Another problem is that all of the payroll data are stored on the supplier's computer, rather than that of the company, so that i tis impossible to automatically link payroll data to other reports that are compiled by the in-house computer system. It is also difficult to convert to a payroll supplier if this is not done at the end of the calendar year, since suppliers will not be held responsible for incorrect partial-year data that they are given.

Collections - a collection firm is aggressive in going after delinquent pyees, which is both their greatest strength and weakness. Company may lose some key customers, if collestion firm go to excessive lengths to collect funds from key customers. Another problem is that collection firms usually charge as their fee part of amount collected. For these reasons, the usual outsourcing solution in this area is to give to a collections firm only the unpaid invoices of those customers with whom a company no longer wishes to do business, and only after it has expended a reasonable amount of collections effort through its internal collections group.

Internal audit - there are a several serious issues that counterbalance large number of advantages. Large auditing firms have very high overhead and therefore charge rates that are much higher than the amounts required to cover the salaries of their auditors. These rates can 
be reduced by a minimum number of auditing hours per year, the cost per hour will be much higher than with an in-house staff. Another problem is that some companies like to assign promising employees to the internal audit staff, so that they can rapidly rotate through a number of departments as part of their internal audits - if this function is outsourced the training role disappears. Outside auditors also tend to bring in some proportion of their staffs who have little experience on the grounds that they have to provide training for their personnel, this will lower the efficiency of audits, but can be avoided by insisting on the use of more experienced auditors. Sometimes To keep internal audit work separated from its financial statement audit work the company is hiring two audit firms, one audit firm for annual audit and another for the internal audit. Given the number of issues with the use of external auditors, $i$ tis more common to see them used in an occasional supporting role than to take over the entire function.

Financial statement preparation - to provide this function by outside accounting firm will be much more expensive than if the same tasks were completed by an in-house staff.

Transaction processing - though there is some chance that shifting the bulk of a company's transaction processing activities to a supplier will result in a drop in sosts, this will only be the case if the supplier can operate the department at a significantly lower cost, add on its profit margin, and still arrive at a cost lower than what was being achieved. Also, there must still be a few accountants left at the company to acta s overseers of the supplier's activities, so their cost must be added to the costs charged by the supplier. Consequently, the odds of achieving a grand total lower cost by shitfing transaction processing to a supplier are not high. [1]

\section{Conclusion}

Outsourcing is aviable option for those managers who are interested in improving the efficiency and effectiveness of the accounting department. However, it can also be an expensive approach that does not necessarily produce better results than could be obtained by performing the same tasks internally. The key to ensuring the best results is to segment the accounting department into a group of functions and to explore in great detail the efficacy of outsourcing for each one. I tis quite likely that there will be a role for outsourcing somewhere in the department after this analysis has been completed, though probably not for the entire department. For a larger accounting department that is fully staffed in all functional areas, i tis less expensive to keep all work internal, as long as all areas are properly managed.

\section{Literatúra}

[1] Bragg, Steven M.: Just in time accounting, 2001 John Wiley \& sons, ISBN 0-471-392111

[2] Bragg, Steven M.: Outsourcing, 2006 John Wiley \& sons, ISBN 978-0-471-67626-3

[3] Institu of management and administration (IOMA): Cost reduction and control - Best practices, 2006 IOMA, ISBN - 10: 0-471-73918-9

[4] Power, Mark J.; Desouza, Kevin; Bonifazi, Carlo: The outsourcing hand book - How to implement a successful outsourcing process, 2006 London, Cogan page, ISBN 0749444304

[5] Bragg, Steven M.: Financial analysis - Controllers guide, 2007 John Wiley \& sons, ISBN - 10: 0-470-05518-9

[6] www.credit-to-cash-advisor.com/home/articles/outsourcing, [online]. [s.a.]. [Citované 2009-06-06].

[7] www.articlesbase.com, [online]. [s.a.]. [Citované 2009-06-06]. 